\title{
Application of a job-exposure matrix to national mortality statistics for lung cancer
}

\author{
C MAGNANI, B PANNETT, P D WINTER, D COGGON \\ From the MRC Environmental Epidemiology Unit, University of Southampton, Southampton General Hospital, \\ Southampton SO9 $4 X Y, U K$
}

In 1980 Hoar et al first drew attention to the potential value of job-exposure matrices in the search for new occupational carcinogens. ${ }^{1}$ They used a matrix to reanalyse data from a case-control study of bladder cancer and found a higher relative risk for the group of jobs entailing possible exposure to aromatic amines than for any of the industrial categories that had been examined in the original analysis.

Despite this initial promise, subsequent attempts to enhance hypothesis generating epidemiological surveys by the application of job-exposure matrices have been largely unrewarding. ${ }^{2-4}$ One difficulty is the discrimination of spurious chance associations that inevitably arise when many putative carcinogens are examined simultaneously. One approach to this problem is to grade the exposures associated with jobs and look at dose-response relations. When broken down by exposure grade, however, risk estimates are subject to greater sampling variation, and even in relatively large studies known carcinogens, when examined in this way, have failed to show a clear dose response effect. Better results might be obtained with very large data sets in which risk estimates are statistically more stable.

To test this idea we have applied a job-exposure matrix to data on 31925 deaths from lung cancer derived from the Office of Population Censuses and Surveys (OPCS) 1971 Decennial Supplement on Occupational Mortality in England and Wales. ${ }^{5}$ We have included in the matrix several known and suspected lung carcinogens together with other exposures that are unlikely to cause the disease, and we have concentrated in particular on exposures that are encountered in a range of different jobs since it is for such agents that the matrix method is most likely to offer an advantage over conventional analytical techniques.

Accepted 12 January 1987

\section{Method and results}

Each of the 223 occupational units distinguished in the 1971 Decennial Supplement was classified according to its exposure to the 14 agents and activities listed in table 1. Five grades of exposure were distinguished-background (comparable with that of an unemployed person), low, moderate, high, and "restricted high." The last category was used for occupational units in which a small proportion of workers are highly exposed but most have only background exposure. For example, a few chemical process workers are highly exposed to chromates but most have no contact with such compounds. The assignment of exposures was based on an earlier matrix ${ }^{3}$ but with modifications necessitated by the less specific job classification used in the Decennial Supplement.

From unpublished OPCS material we abstracted the number of deaths from lung cancer in men aged 15-64 during the period 1970-2, broken down by occupational unit and ten year age group. Estimates of the corresponding populations at risk were obtained from the 1971 census. The job-exposure matrix was used to group occupations according to exposure, and standardised mortality ratios (SMRs) were calculated using the rates for all working men as a standard. Confidence limits for SMRs were based on the Poisson distribution.

Three agents-asbestos, chromates, and diesel fumes-showed a significantly raised SMR for occupations with greater than background exposure, and also a progressive increase in SMRs from background through to highly exposed occupations (table 1). For polycyclic aromatic hydrocarbons and organic solvents the overall SMR in exposed occupations was significantly high but the dose response relation was not quite consistent.

Mortality from lung cancer increases steeply from social classes $\mathrm{I}$ to $\mathrm{V}^{5}$ and since many of the exposures under study occur predominantly in manual occupations, some confounding by social class could 
Table 1 SMRs for lung cancer by grade of exposure: men aged 15-64

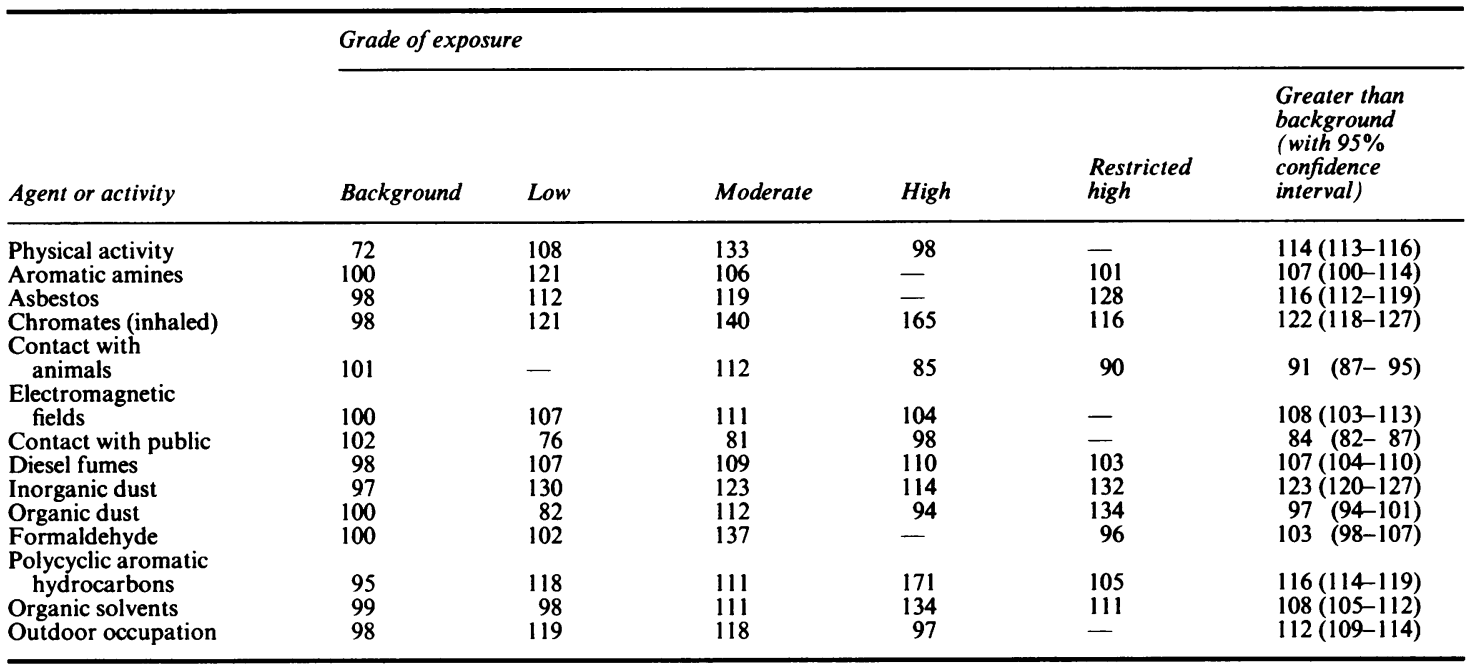

be expected. Social class cannot be inferred from occupation alone as it depends also on employment status (self-employed, foreman, etc). Nevertheless, it was possible to standardise approximately for social class by assigning occupations to the class with which they are most often associated.

The results of this revised analysis are given in table 2. The overall effect of social class standardisation was to weaken associations, to the extent that most ceased to be statistically significant: some even became negative. Mortality was significantly raised for jobs entailing physical activity but the SMR for those with the greatest exposure was only 91 and less than that for sedentary occupations.

\section{Discussion}

The first results achieved in this analysis were encouraging. Two of the three known lung carcinogens included in the matrix, asbestos and chromates, showed significantly raised SMRs and a clear doseresponse effect. The only other exposure to do this, diesel fumes, while not an established cause of lung cancer, has nevertheless been associated with the dis-

Table 2 SMRs for lung cancer by grade of exposure after standardisation by social class: men aged 15-64

\begin{tabular}{|c|c|c|c|c|c|c|}
\hline \multirow[b]{2}{*}{ Agent or activity } & \multicolumn{6}{|c|}{ Grade of exposure } \\
\hline & Background & Low & Moderate & High & $\begin{array}{l}\text { Restricted } \\
\text { high }\end{array}$ & $\begin{array}{l}\text { Greater than } \\
\text { background } \\
\text { (with } 95 \% \\
\text { confidence } \\
\text { interval) }\end{array}$ \\
\hline Physical activity & 92 & 101 & 110 & 91 & - & $103(101-104)$ \\
\hline Aromatic amines & 100 & 105 & 88 & - & 89 & $93(87-99)$ \\
\hline Asbestos & 100 & 94 & 103 & - & 104 & $98(95-101)$ \\
\hline Chromates (inhaled) & 100 & 100 & 123 & 143 & 101 & 102 (99-106) \\
\hline $\begin{array}{l}\text { Contact with } \\
\text { animals }\end{array}$ & 100 & - & 95 & 93 & 103 & $95(91-100)$ \\
\hline \multicolumn{7}{|l|}{ Electromagnetic } \\
\hline fields & 100 & 99 & 98 & 91 & - & $96(92-100)$ \\
\hline Contact with public & 100 & 105 & 89 & 111 & - & $99(96-103)$ \\
\hline Diesel fumes & 101 & 98 & 95 & 96 & 90 & $97(94-99)$ \\
\hline Inorganic dust & 100 & 111 & 100 & 99 & 105 & $102(99-106)$ \\
\hline Organic dust & 101 & 83 & 97 & 81 & 108 & $90(87-94)$ \\
\hline Formaldehyde & 100 & 88 & 120 & - & 100 & $94(90-98)$ \\
\hline \multicolumn{7}{|l|}{ Polycyclic aromatic } \\
\hline hydrocarbons & 100 & 100 & 96 & 148 & 76 & $99(97-101)$ \\
\hline Organic solvents & 101 & 90 & 96 & 116 & 87 & $96(93-99)$ \\
\hline Outdoor occupation & 100 & 109 & 94 & 98 & - & $101 \quad(98-103)$ \\
\hline
\end{tabular}


ease in previous studies. ${ }^{6}$ The third lung carcinogen examined, polycyclic aromatic hydrocarbons, was also significantly associated with lung cancer but the dose response relation was slightly inconsistent.

It was disappointing, therefore, that when allowance was made for the possible confounding effects of social class, the effects of these known carcinogens were much less readily discernible. The highest SMRs were still for jobs with high exposure to polycyclic aromatic hydrocarbons and chromates, but in the absence of a significantly raised SMR for overall exposure to these substances-that is, at levels above background-it is unlikely that much would have been made of either observation without strong a priori suspicion of a hazard. We wondered whether our results might have been influenced by the biases which are known to occur when occupational information from different sources (death certificates and census) is used to derive the numerator and denominator of death rates. ${ }^{57}$ When we reanalysed the data excluding the 19 occupational units which are subject to the most severe reporting bias, however, the outcome was essentially unaltered.

The analysis with standardisation for social class is the more appropriate of the two methods used to look at the data. The gradient in lung cancer mortality by social class cannot be explained simply by the exposure of manual workers to occupational carcinogens, and social class is therefore a true confounder. Our failure to demonstrate clearly the effects of known carcinogens when allowing for social class can probably be attributed to the misclassification that occurs when exposures are inferred from the incomplete and sometimes inaccurate occupational histories available from death certificates. The effect of such misclassification outweighs the greater statistical precision that may be obtained by studying large numbers of deaths.

In view of these findings and our earlier experience, we believe that job-exposure matrices are unlikely to find a major role in the generation of clues to new occupational carcinogens from studies based on the general population. This does not, however, detract from their established value in industrial cohort studies where job titles are more specific and exposures may be inferred with greater accuracy. Nor does it reflect on their application to the estimation of population attributable risks from case-control studies, the use of which has yet to be fully assessed. ${ }^{8}$

We thank Dr M McDowall of OPCS who supplied us with the data from the 1971 Decennial Supplement and advised us about the biases in reported occupations and Dr A Ward Gardner who provided helpful comment on the matrix.

Dr C Magnani carried out this work during the tenure of a research training fellowship awarded by the International Agency for Research on Cancer.

\section{References}

1 Hoar SK, Morrison AS, Cole P, Silverman DT. An occupation and exposure linkage system for the study of occupational carcinogens. J Occup Med 1980;22:722-6.

2 Coggon D, Pannett B, Acheson ED. Use of job-exposure matrix in an occupational analysis of lung and bladder cancers on the basis of death certificates. JNCI 1984;72:61-5.

3 Pannett B, Coggon D, Acheson ED. A job-exposure matrix for use in population based studies in England and Wales. $\mathrm{Br} J$ Ind Med 1985;42:777-83.

4 Magnani C, Coggon D, Osmond C, Acheson ED. Occupation and five cancers: A case-control study using death certificates. $\mathrm{Br} \mathrm{J}$ Ind Med (in press)

5 Office of Population Censuses and Surveys. Occupational mortality 1970-72. Decennial supplement for England and Wales. London: HMSO, 1978. (Series DS No 1).

6 Howe GR, Fraser D, Lindsay J, Presnal B, Yu SZ. Cancer mortality (1965-77) in relation to diesel fume and coal exposure in a cohort of retired railway workers. $J N C I$ 1983;70:1015-9.

7 Heasman MA, Liddell FDK, Reid DD. The accuracy of occupational vital statistics. Br J Ind Med 1958;15:141-6.

8 Macaluso M, Vineis P, Continenza D, Ferrario F, Pisani P, Andisio R. Job-exposure matrices: experience in Italy. In Acheson ED, ed. Job-exposure matrices. Southampton: MRC Environmental Epidemiology Unit, 1983. 